\title{
Iambic and Trochaic Rhythm in Jieyang (Southern Min)
}

\author{
Suki Yiu \\ University of Hong Kong, University of Arizona
}

\section{Introduction}

According to the Iambic/Trochaic Law, there is a perceptual universal where intensity leads to initial prominence while duration leads to final prominence based on extralinguistic evidence (e.g. Bolton 1894, Woodrow 1909, 1951). These two types of durationally asymmetric rhythmic groupings later form the extralinguistic basis of Hayes' $(1985,1995)$ proposal of an asymmetric foot inventory to explain the rhythmic structure in linguistics, referred to as Metrical Stress Theory. However, its application to languages typically considered as tonal is mostly unknown. Crowhurst and Teodocio Olivares' (2014) work on Betaza Zapotec (Oxaca, Mexico) provided a concise review of linguistic rhythmic grouping, and pointed out that earlier studies all tested native speakers of a few languages, among which speech-like stimuli were only used for western European languages (Hay and Diehl 2007, Bhatara et al. 2013, Morgan, Edwards, and Wheeldon 2014). Considering tonal languages spoken in Asia, the more diverse tonal contrast may also interact with tone sandhi and other phenomena described as stress-sensitive (Chen 2000: 285). In particular, the distinction between left and right tonal prominence displayed in bidirectional tone sandhi resembles that of a metrical distinction between iambic and trochaic rhythm.

Given the bidirectional tone sandhi in Teochew (Southern Min), this paper adopts Jieyang (Bao 1990, 1996, Cai 1991, Lin and Chen 1996), known as the standard variety of Teochew, for acoustic measurements and statistical analyses in a minimal prosodic domain of two syllables (Yiu 2018a, 2018b, $2018 \mathrm{c}$, forthcoming). Duration and intensity were used to indicate whether metrical prominence based on predictions of the Iambic/Trochaic Law aligns with tonal prominence in what sense and to what extent if metrical prominence is phonetically meaningful to signalling rhythm in complex tone languages. Audiorecordings of two native speakers were processed with Praat (Boersma and Weenink 2017) and submitted to Linear Mixed Effect Regression (LMER) Models with R (R Core Team 2017) to generate duration (ms) and intensity $(\mathrm{dB})$ estimates for determining whether the durational and intensity contrasts within disyllabic units of both sandhi types are significant. Comparisons of LMER models were also made to check whether sandhi type interacts with syllable position. Based on the statistic comparisons of phonetic measurements, this paper evaluates the hypothesis and predictions based on the Iambic/Trochaic Law.

\section{Bidirectional tone sandhi and rhythmic types}

2.1 Tone inventory and bidirectional sandhi There are six lexical tones in Jieyang for sonorantfinal syllables as listed in (1). The tone numbers from Xu's (2007) description are given featural representations using the features $\mathrm{H}, \mathrm{M}$, and $\mathrm{L}$ based on Bao (1996). Bao noted that the numerical difference between 2 and 1 is ignored, given that 2 and 1 are not contrastive in Teochew (Jieyang). This treatment is also found for the Chaoyang dialect (Yiu 2018b, 2018c: 45, citing Yip 2002: 189).

\footnotetext{
* The author sincerely thanks Diana Archangeli \& Stephen Matthews, Douglas Pulleyblank, Bruce Hayes, René Kager, Jie Zhang, Natasha Warner, Bryan Gick, Marjorie Chan, Björn Köhnlein, Cynthia Clopper, Jon Yip, Jeroen Breteler, Elaine Lau, Katie Lu, and fellow colleagues at the University of Arizona, University of British Columbia, and Ohio State University. This paper has benefited from feedback by the audience, reviewers, and organizers of AMP 2018, TAL 6, MidPhon 22, MFM 25, and Chula-ISSSEAL 2017. The author gratefully acknowledges the generous funding of a Fulbright Award and a Universitas 21 Collaborative Research Grant.
} 
The tonal inventory of Jieyang

\begin{tabular}{cc} 
Tone number $(\mathrm{Xu} 2007)$ & Tone letter (Bao 1996) \\
\hline 33 & $\mathrm{M}$ \\
53 & $\mathrm{HM}$ \\
213 & $\mathrm{LM}$ \\
55 & $\mathrm{H}$ \\
35 & $\mathrm{MH}$ \\
11 & $\mathrm{~L}$
\end{tabular}

Each of the six tones undergoes sandhi to another tone depending on whether the tone is on the first or second syllable of a disyllabic unit, regardless of the tonal content of the trigger. Right dominant tone sandhi refers to tonal changes observed on the left syllable whereas left dominant tone sandhi on the right. For example, the disyllabic unit /HM.MH/ surfaces as [MH.MH] for right dominant tone sandhi but as [HM.L] for left dominant tone sandhi.

When the syllable has a citation tone of /HM/ in the sandhi position of right dominant sandhi, no matter which tone comes after it in the non-sandhi position, $[\mathrm{MH}]$ is found in the sandhi position instead of [HM]. For example, $t^{s} u i$ kuay /HM.HM/ 'water pipe' becomes [MH.HM] after tone sandhi, whereas $t^{s} u i$ liu /HM.H/ 'water flow' becomes [MH.H]. Conversely, when the syllable has a citation tone of /HM/ in the sandhi position of left dominant sandhi, no matter which tone comes before in the non-sandhi position, $[\mathrm{LM}]$ is found in the sandhi position instead of [HM]. For example, liau liau /HM.HM/ 'finished' becomes [MH.LM] after tone sandhi, whereas $\tilde{\imath}$ liau /H.HM/ 'slept' becomes [H.LM]. (2) depicts the full list of sandhi tones based on the respective citation tones for both left and right dominant sandhi.

(2) also shows that right dominant tone sandhi holds four different tones $(\mathrm{H}, \mathrm{M}, \mathrm{L}$, and $\mathrm{MH})$ in its sandhi position, and left dominant position holds only two ( $\mathrm{L}$ and $\mathrm{LM}$ ) in its sandhi position. We will come back to more discussion of this characteristic in Section 5.

Right and left dominant tone sandhi (Xu 2007)

\begin{tabular}{ccc} 
Citation tone & Right dominant tone sandhi & Left dominant tone sandhi \\
\hline M & M & L \\
HM & MH & LM \\
LM & H & L \\
H & L & L \\
MH & L & L \\
L & L & L
\end{tabular}

With bidirectional tone sandhi (Zhang 2007) within one language, not only can we make within sandhi type comparison between the first and second syllables, but also across sandhi type comparison between the citation syllables in both sandhi types, between the sandhi syllables in both types, and between the sandhi syllables and their citation counterparts in the other type. This offers a six-way comparison in terms of duration and intensity to unveil the relative prominence of syllables in different positions within a disyllabic unit of both sandhi types.

Based on the assumption of the relationship between tonal stability and prosodic prominence (Chen 2000), syllables with citation tones are considered to be more prominent than those with sandhi tones. Since right dominant tone sandhi changes the tone on the left, it is expected to pattern with the iambic rhythm. As the left dominant tone sandhi changes the tone on the right, it is expected to behave like trochees.

2.2 Hypothesis and predictions This paper hypothesizes that the Iambic/Trochaic Law (Hayes 1985, 1995) holds for complex tone languages, and thus, tone sandhi is a metrical phenomenon. In terms of duration and intensity, the two sandhi types (left and right dominant) are expected to pattern with the rhythm type (trochees and iambs) associated with each sandhi type. Here are the predictions. 
Predictions

Prediction 1 There are duration and intensity asymmetries between the two sandhi types, where duration contrast is expected for right dominant tone sandhi while intensity is expected for left dominant tone sandhi.

Prediction 2 Sandhi syllables are less prominent than citation syllables in the same syllable position, in terms of duration and/or intensity.

Prediction 3 Citation syllables of different rhythmic types are more prominent in their corresponding phonetic cues, while sandhi syllables are less prominent.

\section{Methodology}

3.1 Subjects Audio-recordings were obtained from two native speakers of Jieyang in their twenties. They were both born and raised in the Jieyang speaking area of the Chaoshan region, China.

3.2 Stimuli The data was elicited with a wordlist of seventy-two disyllabic units, covering all possible tonal combinations for both sandhi types. For example, citation tone $\mathrm{H}$ was paired with each of the six citation tones, so as to obtain data of all six sandhi forms when in combination with another syllable, resulting in six combinations for each tone, and thirty-six combinations for all six tones. After repeating the same process for the two sandhi types, this provides seventy-two combinations. The wordlist was randomized, and produced five times by each speaker. This provides a total of 1440 syllables for analysis (= 6 tones $\mathrm{x} 6$ tones $\mathrm{x} 2$ syllables $\mathrm{x} 2$ sandhi types $\mathrm{x} 5$ iterations $\mathrm{x} 2$ speakers).

The design of the wordlist made exhausting the tonal combinations a priority, and used real words instead of nonce words to ensure expected sandhi effects. Onset (nil, sonorant, aspirated stop, non-aspirated stop), vowel height (high, mid, low), and coda (nil, nasal, stop) were treated as random factors in the LMER models presented in the next section, so as to minimise their influence on distracting our models from testing the metrical hypothesis. For the morphosyntactic structure, constructions included are compounds, noun phrases, verb phrases, adjectival phrases, and adverbial phrases.

3.3 Data collection and analysis The data was recorded in a sound booth using an earset microphone, attaching to a portable digital recorder at a sampling frequency of $44100 \mathrm{~Hz}$, monitored by the experimenter with a headphone set. The subjects were presented with the randomised words on a laptop one at a time, and were asked to read the words in a natural way. Subjects were also asked to fill in a language background questionnaire after the recording session so as to provide information on the specific Teochew dialect that they speak and potential interference from other dialects or languages to the one under investigation.

Segmentation of the recordings, and extraction of syllable duration and maximal intensity were performed in Praat (Boersma and Weenink 2018). The duration and intensity measurements were compiled as a main data file to submit to Linear Mixed Effect Regression models in R (R Core Team 2018). lmerTest (Kuznetsova et al. 2017) was adopted in order to generate estimates for disyllabic units at both positions (i.e. the first and second syllables) of two sandhi types (i.e. right dominant and left dominant tone sandhi) for determining whether the durational and intensity contrasts of each estimate point are significantly different from each other in the expected direction under the Iambic/Trochaic Law (Hayes 1985, 1995). $P$ values were calculated with the Satterthwaite approximation, one of the most conservative methods of $p$ value calculation for LMER models having a small number of subjects (Luke 2017). Comparisons of LMER models were also made to check whether sandhi type interacts with syllable position.

\section{Results}

The LMER model for both duration and intensity consists of fixed effects of sandhi type (left dominant and right dominant) and position of syllable (first, second). As random effects, there are intercepts for items, speakers, onset, vowel height, coda. Since sandhi type and position of syllable are important factors 
to our model, the model has also specified the by-speaker and by-item random slopes for the effect of position of syllable. It has also specified the by-speaker random slope for the effect of sandhi type. ${ }^{1}$

$P$-values obtained by likelihood ratio tests indicate that the interaction is significant between sandhi type and position of syllable for both duration $\left(\chi^{2}(1)=14.281, p=0.0001574\right)$ and intensity $\left(\chi^{2}(1)=\right.$ 18.024, $p=2.181 \mathrm{e}-05)$. Adding the interaction improves the additive model. The effect of sandhi type increases over the course of a disyllabic unit for both duration and intensity.

Figures 1 and 2 display the plots of LMER estimates of duration and intensity respectively. Right dominant tone sandhi is in pink and left dominant tone sandhi is in blue. The estimates are listed at the bottom of each corresponding figure.

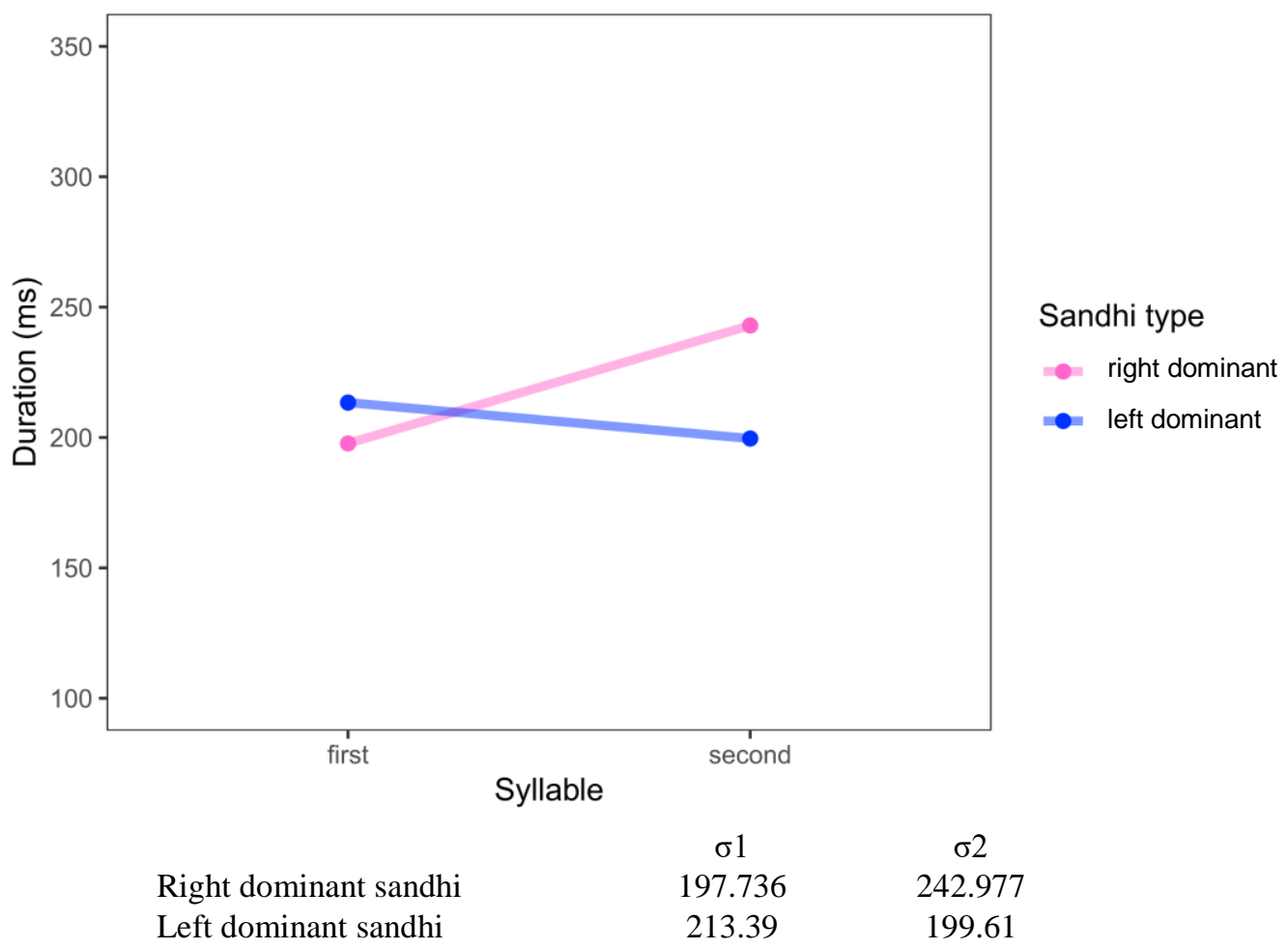

Figure 1. Plot of LMER estimates of duration (ms) for right dominant (pink) and left dominant tone sandhi (blue)

\footnotetext{
${ }^{1}$ Some argue that models should be kept maximal even though the inclusion of a factor does not significantly improve the model. Please refer to Barr, Levy, Scheepers and Tilly (2013) for more details.
} 


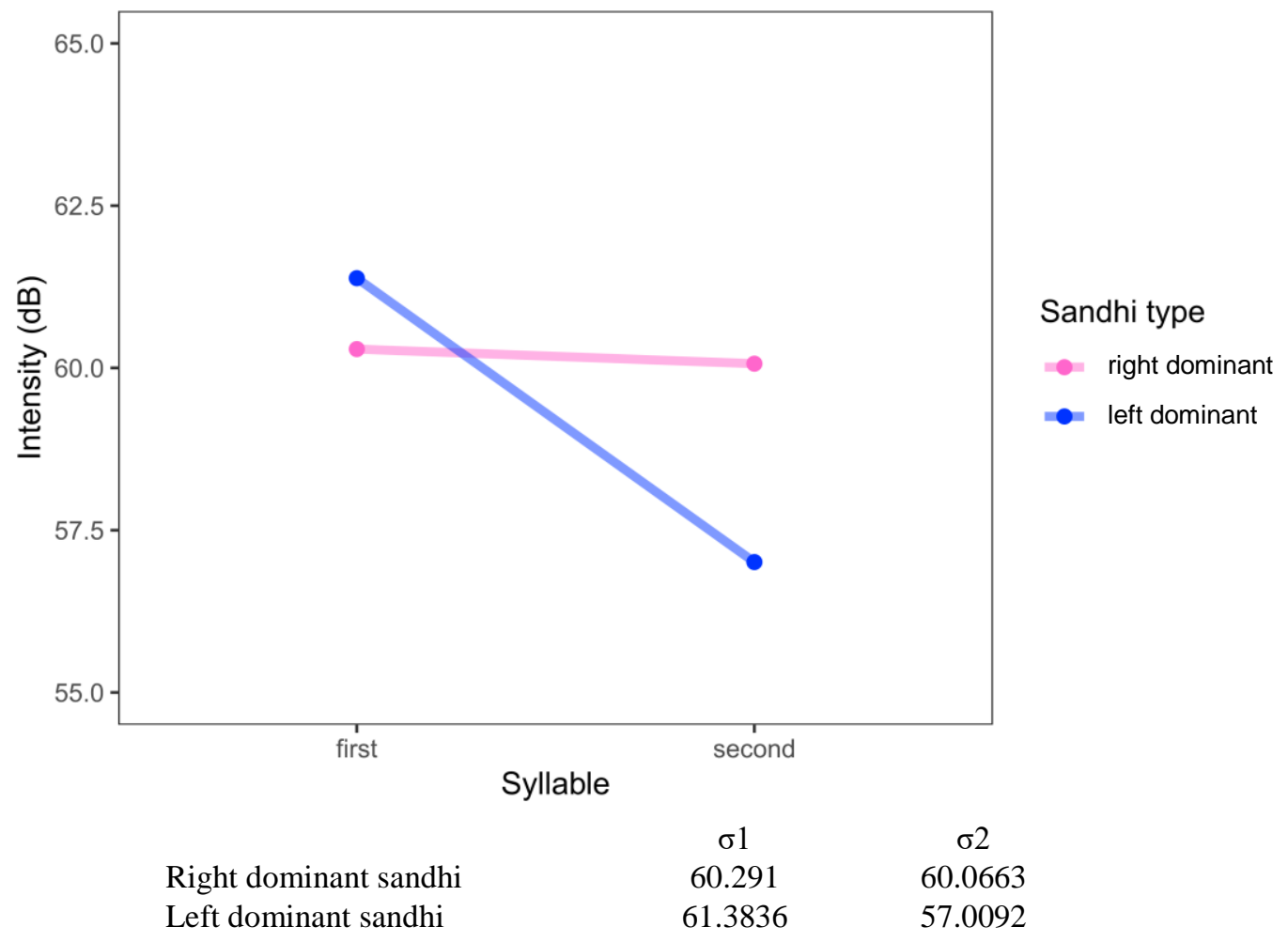

Figure 2. Plot of LMER estimates of intensity $(\mathrm{dB})$ for right dominant (pink) and left dominant tone sandhi (blue) $)^{2}$

Based on the three predictions in Section 2.2, the six pairwise comparisons required are listed below:

(4) Six-way comparisons with bidirectional tone sandhi

Prediction 1 R1 vs. R2 Within sandhi type comparisons between the more prominent and L1 vs. L2 less prominent positions

Prediction 2 R1 vs. L1 Cross-sandhi type comparisons between the more prominent and R2 vs. L2 less prominent positions of the two sandhi types in the same position of syllable in a disyllabic unit

Prediction 3 R1 vs. L2 Cross-sandhi type comparisons between the less prominent position L1 vs. R2 of each sandhi type, and between the more prominent position of each sandhi type

In order to make pairwise comparisons between the estimated values of duration (ms) and intensity (dB), the chosen model needs to provide $p$-values from comparing the estimated values for each of the six pairs in (4). However, the interactive model above returns estimated values for the citation-citation comparison and the sandhi-sandhi comparison of Prediction 3 in interactive terms instead of making a direct comparison. Instead, a model with a combined factor of sandhi type and position of syllable, such that the

${ }^{2}$ For reference, studies in music perception show that the Just Noticeable Difference for intensity is around $1 \mathrm{~dB}$ for humans, mediated by frequency and initial loudness of the sound (Mills 1960, Middlebrooks and Green 1991, Forinash and Christian 2016). Intensity differences of around $5 \mathrm{~dB}$ have been reported as correlates of sentence stress in English, and those of word stress are even smaller (Heuven 2014, citing Lea 1977, Beckman 1986). 
four positions of both sandhi types (R1, R2, L1, and L2) can exhaust the six-way comparison. ${ }^{3}$

Further examination showed that the full combined factor model would not converge for some of the six pairwise comparisons, either in terms of duration or intensity. Therefore, when comparing the estimated values, a conservative version of the combined factor model which omitted the random slopes was used instead. Results of the pairwise comparisons will be presented in the next section to evaluate the hypothesis and predictions based on the Iambic/Trochaic Law.

\section{Discussion}

This section evaluates the three predictions based on the metrically motivated hypothesis in terms of estimated values of duration (ms) and intensity $(\mathrm{dB})$ for different comparisons using LMERs. The relevant pairwise comparisons in terms of duration and intensity are extracted for discussing each of the predictions. For the convenience of description, I will refer to the first and second syllables of right dominant tone sandhi as R1 and R2; and those of left dominant tone sandhi as L1 and L2. Citation tone syllables are boldfaced.

Table 1 shows the two pairs for evaluating Prediction 1, which include the first and second syllable of right dominant sandhi (i.e. R1 vs. R2), and the first and second syllable of left dominant sandhi (i.e. L1 vs. L2).

\begin{tabular}{|c|c|c|c|c|c|c|}
\hline & & est. 1 & est. 2 & $t$ & $p$ & sig. \\
\hline \multirow[t]{2}{*}{ Duration (ms) } & R1 vs. R2 & 197.736 & 242.977 & 11.197 & $<2 \mathrm{e}-16$ & $* * *$ \\
\hline & L1 vs. L2 & 213.39 & 199.61 & -3.831 & 0.000133 & $* * *$ \\
\hline \multirow[t]{2}{*}{ Intensity (dB) } & R1 vs. R2 & 60.291 & 60.0663 & -0.699 & 0.4938 & n.s. \\
\hline & L1 vs. L2 & 61.3836 & 57.0092 & -13.939 & $<2 \mathrm{e}-16$ & $* * *$ \\
\hline
\end{tabular}

Table 1. Pairwise comparisons for Prediction 1

For Prediction 1, the metrical hypothesis predicts duration and intensity asymmetries between the two sandhi types. Specifically, duration contrast is expected for right dominant sandhi whereas intensity is expected for left dominant sandhi. In Table 1, for duration, syllables within a disyllabic unit contrast significantly for both sandhi types. On the other hand, the intensity contrast is significant only for left dominant sandhi but not for right dominant sandhi, resulting in an intensity asymmetry as predicted by the metrical hypothesis. By looking at the intensity asymmetry, left and right dominant sandhi maps neatly with trochaic and iambic rhythm respectively.

We will examine the details of the relative prominence of syllables in different positions within disyllabic units of the two sandhi types in terms of duration and intensity via Prediction 2 and Prediction 3.

For Prediction 2, sandhi syllables are predicted to be less prominent than citation syllables in the same position of syllable in terms of duration and intensity. As explained in the above, when holding the position of syllable constant, the sandhi syllable of right dominant sandhi (R1) is expected to be shorter and quieter than the citation syllable of left dominant sandhi (L1). Similarly, the sandhi syllable of left dominant sandhi (L2) is expected to be quieter and shorter than the citation syllable of right dominant sandhi (R2).

\footnotetext{
${ }^{3}$ When compared with the interactive model, the combined factor model shares the identical estimated values for all conditions, and the same $p$-values for four out of the six pairwise comparisons except the two in Prediction 3 which are problematic for our purpose as mentioned. With a model having a combined factor, it is able to return significance values of those two pairs from direct comparisons.
} 


\begin{tabular}{|c|c|c|c|c|c|c|}
\hline & & est. 1 & est. 2 & $t$ & $p$ & sig. \\
\hline \multirow[t]{2}{*}{ Duration (ms) } & R1 vs. L1 & 197.736 & 213.39 & 2.510 & 0.0136 & $*$ \\
\hline & R2 vs. L2 & 242.977 & 199.61 & 6.821 & $4.82 \mathrm{e}-10$ & $* * *$ \\
\hline \multirow[t]{2}{*}{ Intensity $(\mathrm{dB})$} & R1 vs. L1 & 60.291 & 61.3836 & 2.307 & 0.0226 & $*$ \\
\hline & R2 vs. L2 & 60.0663 & 57.0092 & 2.307 & 0.0226 & $*$ \\
\hline
\end{tabular}

Table 2. Pairwise comparisons for Prediction 2

As seen in Table 2, R1 is significantly shorter and quieter than L1, as predicted by the metrical hypothesis. Table 2 also shows that L2 is significantly shorter and quieter than R2, as predicted by the metrical hypothesis. The results agree with the metrical view that prosodic heads are more prominent than nonheads in a way that also conforms with the Iambic/Trochaic Law.

For Prediction 3, citation syllables of different rhythmic types are predicted to be more prominent in their corresponding phonetic cues in terms of duration and intensity, while sandhi syllables are less prominent. As explained in the above, when comparing the citation syllables of left and right dominant sandhi, that is L1 and R2, L1 is expected to be louder but shorter than R2. When comparing the sandhi syllables of left and right dominant sandhi, R1 is expected to be shorter but louder than L2.

\begin{tabular}{|l|l|c|c|c|c|c|}
\hline \multicolumn{2}{|c|}{} & est. 1 & est. 2 & $t$ & $p$ & sig. \\
\hline \multirow{2}{*}{ Duration (ms) } & R1 vs. L2 & 197.736 & 199.61 & 0.296 & 0.7680 & n.s. \\
\cline { 2 - 8 } & L1 vs. R2 & 213.39 & 242.977 & 4.792 & $5.53 \mathrm{e}-06$ & $* * *$ \\
\hline \multirow{2}{*}{ Intensity (dB) } & R1 vs. L2 & 60.291 & 57.0092 & -6.778 & $3.20 \mathrm{e}-10$ & $* * *$ \\
\cline { 2 - 8 } & L1 vs. R2 & 61.3836 & 60.0663 & -2.928 & 0.00468 & $* *$ \\
\hline
\end{tabular}

Table 3. Pairwise comparisons for Prediction 3

Table 3 shows that L1 is significantly louder and shorter than R2, as predicted by the metrical hypothesis. Also, R1 is significantly louder than L2 and shows a non-significant tendency towards being shorter than L2 as predicted.

This indicates that the prosodic heads of the two sandhi types tend to be more prominent particularly in duration or intensity depending on whether the head is initial or final within a disyllabic unit, as expected for iambs and trochees. Conversely, the prosodic non-heads of the two sandhi types tend to be less prominent particularly in duration or intensity depending on whether the non-head is initial or final within a disyllabic unit, just as expected for iambs and trochees respectively. The duration contrast and intensity contrast match the metrical predictions based on the Iambic/Trochaic Law.

Thus far, the metrical view of prominence based on duration and intensity contrasts largely matches the tonal view based on tonal behaviours in Jieyang. Among all components involved in the comparisons of the three predictions, the only pattern surfacing not as predicted is the duration asymmetry in Prediction 1 , where an unexpected duration contrast is found for left dominant tone sandhi. Besides, considering both duration and intensity, the sandhi syllable of left dominant sandhi (L2) seems to be less prominent than the sandhi syllable of right dominant sandhi (R1). This matches the smaller sandhi tone inventory for left dominant sandhi (two tones) than right dominant sandhi (four tones), as mentioned in Section 2.1.

\section{Conclusions}

This paper has illustrated the application of the Iambic/Trochaic Law to complex tone languages like Jieyang (Teochew, Southern Min). With bidirectional tone sandhi on top of its six-tone inventory, LMER results based on duration and intensity measurements confirmed an interaction between rhythmic type and sandhi type. Results also showed that prominence in terms of duration and intensity contrasts largely behaves the way as predicted by the Iambic/Trochaic Law. 
This paper has provided novel support for metrical prominence of tone languages based on the Iambic/Trochaic Law, adding complex tone languages and production results to the recent literature on rhythmic groupings by Crowhurst and others. It showed that tone sandhi can be metrically-motivated via duration and intensity, contributing to the rhythmic organization of tone languages altogether. Future research can look into the morphosyntactic and semantic structure of the two sandhi types, and longer prosodic domains.

\section{References}

Bao, Zhiming. 1990. On the Nature of Tone. Doctoral Dissertation, Massachusetts Institute of Technology, Cambridge.

Bao, Zhiming. 1996. Teochew Tone Sandhi and the Representation of Tone, Pan-Asiatic Linguistics: Proceedings of the 4th International Symposium on Languages and Linguistics 1, 25-46.

Barr, Dale, Roger Levy, Christoph Scheepers, and Harry Tily. 2013. Random effects structure for confirmatory hypothesis testing: Keep it maximal. Journal of Memory and Language 68:3, 255-278.

Beckman, Mary. 1986. Stress and Non-Stress Accents. Dordrecht, the Netherlands: Foris Publications.

Bhatara, Anjali, Natalie Boll-Avetisyan, Annika Unger, Thierry Nazzi, and Barbara Höhle. 2013. Native language affects rhythmic grouping of speech. Journal of the Acoustical Society of America 134:5, 3828-3843.

Boersma, Paul, and David Weenink. 2017. Praat: doing phonetics by computer [computer program]. Version 6.0.36. http://www.praat.org. (accessed 21 February 2018)

Bolton, Thaddeus. 1894. Rhythm. American Journal of Psychology 6, 145-238.

Cai, Jun Ming. 1991. Chaozhou Fangyan Cihui [A Dictionary of Chaozhou Dialect]. Institute of Chinese Culture, Chinese University of Hong Kong.

Chen, Matthew. 2000. Tone Sandhi: Patterns across Chinese Dialects. Cambridge: Cambridge University Press.

Crowhurst, Megan, and Amador Teodocio Olivares. 2014. Beyond the Iambic-Trochaic Law: the joint influence of duration and intensity on the perception of rhythmic speech. Phonology 31:1, 51-94.

Forinash, Kyle, and Wolfgang Christian. 2016. Sound: An Interactive EBook. Retrieved February 23, 2018, from https://www.compadre.org/books/SoundBook

Hay, Jessica, and Randy Diehl. 2007. Perception of rhythmic grouping: testing the iambic/trochaic law. Perception and Psychophysics 69:1, 113-122.

Hayes, Bruce. 1985. Iambic and trochaic rhythm in stress rules. In Mary Niepokuj, Mary VanClay, Vassiliki Nikiforidou and Deborah Feder (eds.) Proceedings of the 11th Annual Meeting of Berkeley Linguistics Society, $429-446$.

Hayes, Bruce. 1995. Metrical Stress Theory: Principles and Case Studies. Chicago: University of Chicago Press.

Kuznetsova, Alexandra, Per Bruun Brockhoff, and Rune Haubo Bojesen Christensen. 2017. lmerTest Package: Tests in Linear Mixed Effects Models. Journal of Statistical Software 82:13, 1-26.

Lea, Wayne. 1977. Acoustic correlates of stress and juncture. In Larry Hyman (ed.) Studies in stress and accent, Southern California occasional papers in linguistics 4, 83-119.

Lin, Lun, and Xiaofen Chen. 1996. Guangdong Min fangyan yuyin yanjiu [On the phonology of Min dialects in Guangdong]. Shantou, Shantou University Press.

Luke, Steven G. 2017. Evaluating significance in linear mixed-effects models in R. Behavior Research Methods 49:4, 1494-1502.

Middlebrooks, John, and David Green. 1991. Sound Localization by Human Listeners. Annual Review of Psychology 42, 135-159.

Mills, A. W. 1960. Lateralization of high-frequency tones. Journal of the Acoustical Society of America 32, $132-134$.

Morgan, Jane, Stephanie Edwards, and Linda Wheeldon. 2014. The relationship between language production and verbal STM: the role of stress grouping. Quarterly Journal of Experimental Psychology 67:2, 220-246.

R Core Team. 2017. R: A language and environment for statistical computing. R Foundation for Statistical Computing, Vienna, Austria. URL https://www.R-project.org/. Version 3.4.3. (last accessed 21 February 2018).

Van Heuven, Vincent. 2014. Acoustic correlates and perceptual cues of word and sentence stress: Mainly English and Dutch. In Carlos Gussenhoven, Yiya Chen and Dan Dediu (eds.) Proceedings of the 4th International Symposium on Tonal Aspects of Languages, 217-228.

Woodrow, Herbert. 1909. A Quantitative Study of Rhythm. Archives of Psychology (New York) 14, 1-66.

Woodrow, Herbert. 1951. Time Perception. In Stanley Stevens (ed.) Handbook of Experimental Psychology, Wiley, New York, New York, 1224-1236.

$\mathrm{Xu}$, Huiling. 2007. Aspect of Chaozhou Grammar A Synchronic Description of the Jieyang Variety. Journal of Chinese Linguistics Monograph Series 22.

Yip, Moira. 2002. Tone. Cambridge: Cambridge University Press. 
Yiu, Suki. 2018a. Metrical and tonal prominence in Swatou. In Hansjörg Mixdorff (ed.) Proceedings of the 6th International Symposium on Tonal Aspects of Languages, 159-163.

Yiu, Suki. 2018b. Stress and tonal prominence in Chaoyang. In Pittayawat Pittayaporn, Sujinat Jitwiri-yanont, Pavadee Saisuwan and Bhimbasistha Tejarajanya (eds.) Journal of the Southeast Asian Linguistics Society, 186-194.

Yiu, Suki. 2018c. The Iambic/Trochaic Law and bidirectional tone sandhi in Teochew languages. Doctoral Dissertation, University of Hong Kong.

Yiu, Suki. Forthcoming. Phonetic evidence for Iambic/Trochaic Law effects in Chaozhou. Proceedings of the 19th International Congress of Phonetic Sciences.

Zhang, Jie. 2007. A directional asymmetry in Chinese tone sandhi systems. Journal of East Asian Linguist 16:4, 259302. 